\title{
UNIVERSITY CAMPUS AND STUDENTS' EMOTIONS: THE ROLE OF LANDSCAPE
}

\author{
LAMIS HANI, DINA MAMDOUH NASSAR \& ALI BAKR \\ Architectural Engineering Department, Faculty of Engineering, Alexandria University, Egypt
}

\begin{abstract}
In university campuses, interaction between the campus users and the physical environment takes place, where students are subjected to daily stress and mental fatigue, great concern must be given to university students for fostering a successful learning experience on campus. This research aims to study the effect of landscape elements within the university campus on students' emotions. This study is divided into two sections; the first is a review of the landscape elements and students' emotions on campus. The second is an analysis of the effects of landscape elements on students' emotions. The research conducted a questionnaire; the findings were illustrated in the form of a two-dimensional matrix between landscape elements and students' emotions. The results of this research have proven that student-landscape interaction on campus often affects students' emotions positively, however, depending on some emotional and landscape preferences, negative emotions might be experienced while viewing or using landscape elements.
\end{abstract}

Keywords: landscape, university campus, emotions, learning environment, academic performance.

\section{INTRODUCTION}

University campus is composed of roads, buildings, and spaces, forming a physical environment, just like the urban pattern, but with a smaller scale [1]. For some people, the landscape is considered as a complementary element that is used in the open spaces surrounding buildings and facilities, disregarding its great impact on the users' emotions leading to a change in their behaviour, attitude, and quality of life, as what was mentioned by Mitchell et al. [2] about the factors affecting the quality of life, and they are health, security, physical environment, personal development and community development [1].

Meyer and Turner [3] defined human emotions as complicated psychological states which take place psychologically, then they affect human behaviour, cognition, and feelings. Although students' emotions are originated with their personality and in their original environments, however, interaction with the physical environment, with all of its components, including landscape, plays an important role in affecting these emotions [4].

As illustrated by Dober [5] if the landscape experience is convenient, nice, functional, exciting, and safe, then the landscape is in good order [4]. The objective of this research is to foster students' positive emotions on campus by using the appropriate landscape elements that form a successful experience in the campus open spaces, leading to a development in students learning and academic performance and achievement.

To achieve the objective of the research, it followed inductive and deductive methodology starting from the literature review to the results section. The research is divided into two sections, the first section is a theoretical framework using a literature review that discusses and analyses students' emotions as a result of their interaction with landscape elements on campus, the second section is a two-phase section, where phase one was an analysis to different landscape scenes that was taken in the three case studies according to Kaplan's theory of landscape preferences for preferable environments, while in phase two a questionnaire was conducted to monitor the emotional states of students to the different landscape elements available in the scenes chosen in phase one. The results of the questionnaire were then represented in the form of a two-dimensional matrix between the 
landscape elements on campus and students' emotions resulting from the interaction with these landscape elements, the research is then continued by a discussion of the matrix results and findings, and a general conclusion.

\section{LITERATURE REVIEW}

\subsection{Emotions and the physical environment in university campuses}

Hockenbury and Hockenbury defined emotions as a complex psychological state [6]. Most theorists stated that basic emotions are natural, general, and obvious states, which develop to serve adaptive functions, all other emotions can be formed by combining any of the basic emotions. As Giacomoni discussed [7] Descartes suggested that the six basic emotions, which are joy, sadness, love, desire, hatred, and wonder, can be combined to form all other emotional states [8]. However, the most famous basic emotions list is called "the big six" by Ekman [9]. His list included happiness, sadness, fear, surprise, anger, and disgust. And then came another theorist, such as Pultchik, Ekman, and Levenson, who kept on adding to the list [10]. As an example for the lists of emotions is Pultchik's Wheel of Emotions, which is similar to the idea of the colour wheel, where combining two colours produces a third colour, in Pultchik's wheel also the combination of two emotions results in a third emotion [11]. The importance of emotions in students learning life is being taken into consideration lately in educational research. As Pekrun et al. [12] stated in 2010, emotions can be considered as an important part of the learning process, as they were found to be related to students' productivity, quality of learning, and well-being. In Harvard University, a department of counselling and mental health services was specified to manage students mental health and well-being, including the importance of students' emotions in their activities, they started multi-session workshops in 2019, for introducing new approaches for participants on handling their feelings and emotions [13].

Studies had proven that the urban space has several factors affecting peoples' emotions, among these factors is the landscape elements used in this space, where people live, grow, work, and perform. Although the human-landscape interaction has been studied in many ways, the emotional value of landscape elements has been neglected [14].

\subsection{Landscape in university campus}

Outdoor space, as said by Ashihara [15], is a building without a roof, where a connection between man and things takes place. The successful design of the urban space depends on the balance between some design standards regulating the human-space relationship [16].

There are two basic informational domains based on Kaplan and Wendt [17] contributions for landscape preferences in the most preferred environments (LEEP), these two domains are understanding and exploration. By combining these two domains, four distinctive patterns were generated. These patterns are complexity, which refers to the number of different elements in the scene, coherence, defined as providing a sense of order to the scene, by using patterns of brightness, size, and texture to drive attention to the scene, legibility, by easily understanding and remembering the place, and mystery, which is the ability of the scene to offer more, encouraging exploration. These four patterns have created a framework for landscape researches for creating the characteristics of the preferable environment [18].

As Law Olmsted [19] stated that the enjoyment of scenery employs the mind without fatigue and yet exercises it, tranquilizes it and yet enlivens it and thus, through the influence of the mind over the body gives the effect of refreshing rest and reinvigoration to the whole 
system. University campus is a reliable opportunity for promoting positivity for its users, affecting their behaviour. However, students in university campuses are usually subjected to a high level of stress, referring to a malfunction between the campus environment and the students' needs. Landscaping the outdoor spaces of university campuses is among the essential factors that affect the campus users, students specifically [20]. Humans can bond emotionally with the surrounding landscape. Thus, studying the relationship between landscape elements and students' emotions in the university campus can contribute to applying the optimum design for the landscape elements used on campus [21].

\subsection{Linking landscape elements to students' emotions on campus}

Landscape elements on campus vary between soft landscape elements and hard landscape elements. The most common landscape elements used in university campuses are: vegetation, water features, outdoor space furniture including seats and benches, bollards, trash cans, kiosks and public art, in addition to lighting elements, signage, circulation features including gates, edges, and paths, and finally parking utilities [22].

\section{METHODS AND MATERIALS}

\subsection{Methods}

The method used in this research is two-phased addressing the effect of landscape elements on university students' emotional states. Primary references were used in data collection weather by gathering information from universities' administration offices or by students' questionnaires. Phase one focused on landscape preferences (LEEP), as discussed by Kaplan, and their application on the three chosen case studies. In phase two, a questionnaire was used to monitor students' emotional responses to the selected landscape scenes from phase one.

The objective of phase one was to determine the optimum landscape scenes in the three universities that would evoke students' emotional responses to the questionnaire, while the objective of phase two was to analyse the emotional responses to the selected scenes to create a two-dimensional matrix correlating students' emotion on using the different landscape elements on campus which can be used by landscape architects to create a successful landscape experience on campus.

\subsection{Materials}

\subsubsection{Study area}

Three universities were chosen for the case study where questionnaires would be distributed, all of the three universities are in Alexandria so that the cultural factor would be constant, these three universities are Arab Academy for Science and Technology (AAST), Pharos University in Alexandria (PUA), and Faculty of Engineering Alexandria University (EAU).

The first university campus in the case studies is one of the oldest governmental campuses in Alexandria, it is the Faculty of Engineering campus (EAU). The total area of the campus is about $109,600 \mathrm{~m}^{2}$, distributed as shown in Fig. 1. The second university campus in the case studies is Arab Academy for Science and Technology AAST. The total area of the campus is about $165,018 \mathrm{~m}^{2}$, distributed as shown in Fig. 2. The third and last university in the case studies is Pharos University in Alexandria PUA. The total area of the campus is about $175,740 \mathrm{~m}^{2}$, distributed as shown in Fig. 3.

Phase 1 was conducted to analyse landscape scenes in each of the chosen case studies, according to the landscape preferences for preferred environments (LEEP) Stated by Kaplan, 
74 The Sustainable City XIV

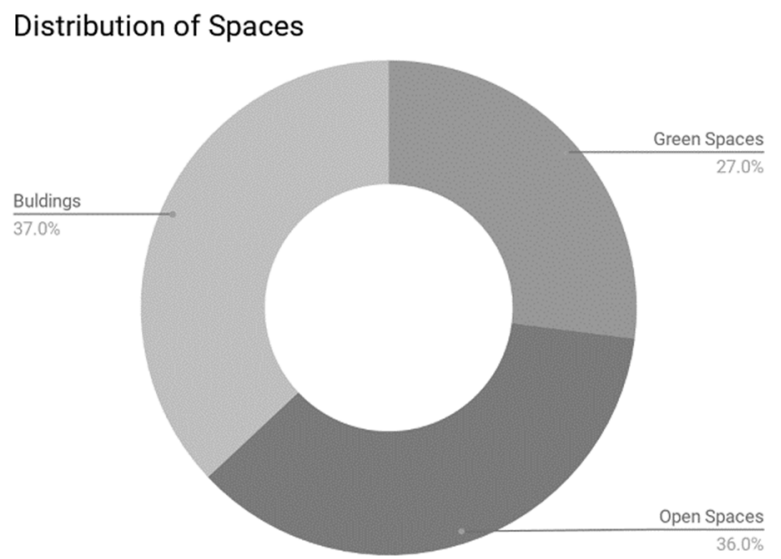

Figure 1: Distribution of spaces in Faculty of Engineering, Alexandria University, Egypt (EAU).

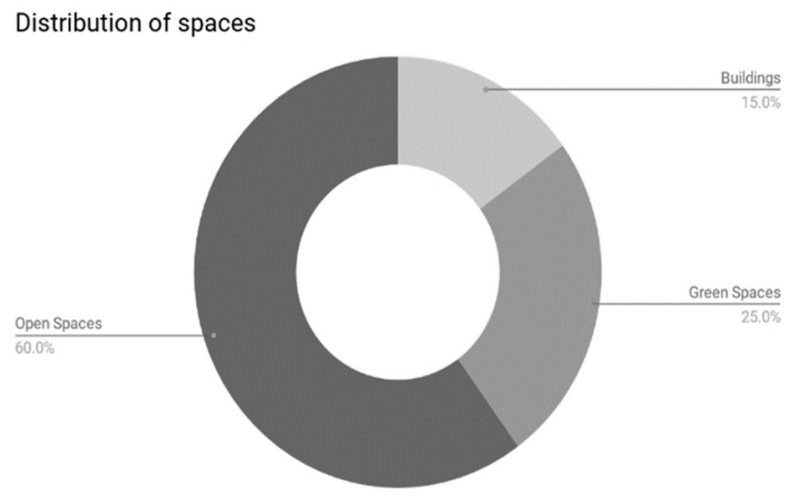

Figure 2: Distribution of spaces in Arab Academy for Science and Technology, Alexandria, Egypt (AAST).

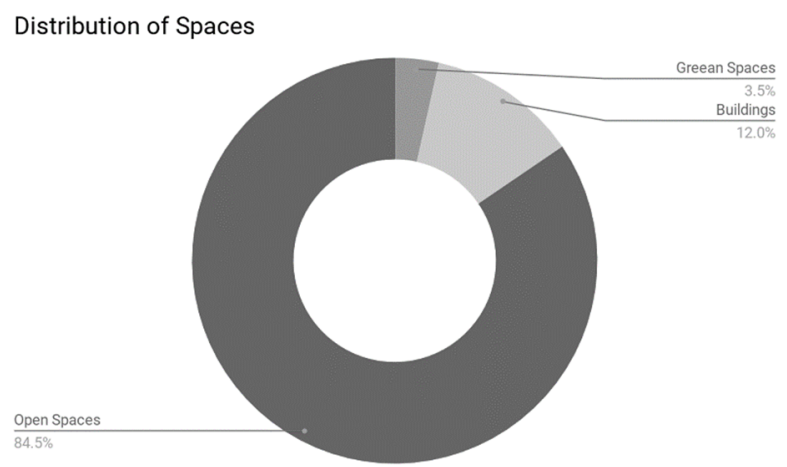

Figure 3: Distribution of spaces in Pharos University in Alexandria, Egypt (PUA). 
which are Complexity, Coherence, Legibility, and Mystery. This was achieved by taking pictures of the different open spaces with different landscape elements in each campus, as shown in Figs 4-6 and comparing the different scenes as shown in Table 1.

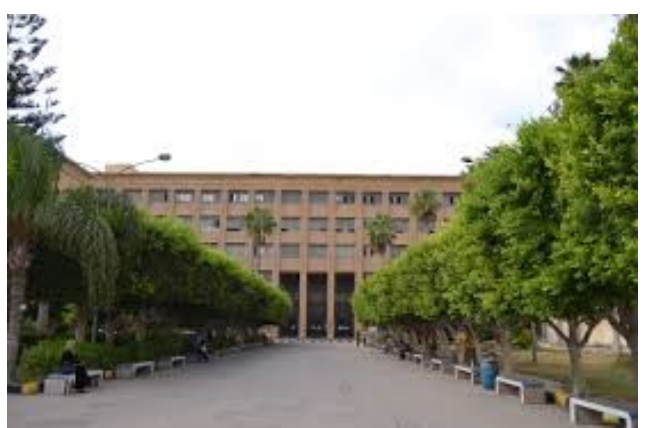

(a)

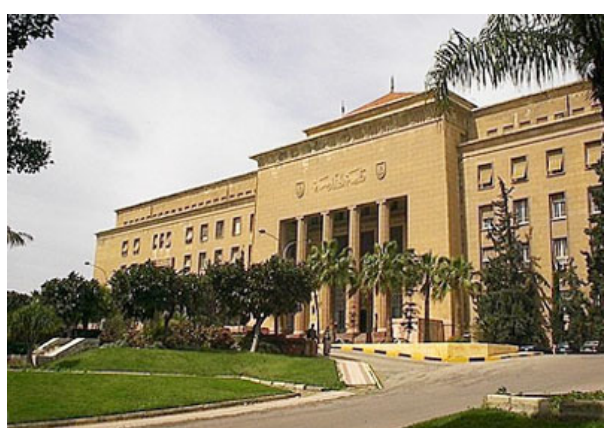

(b)

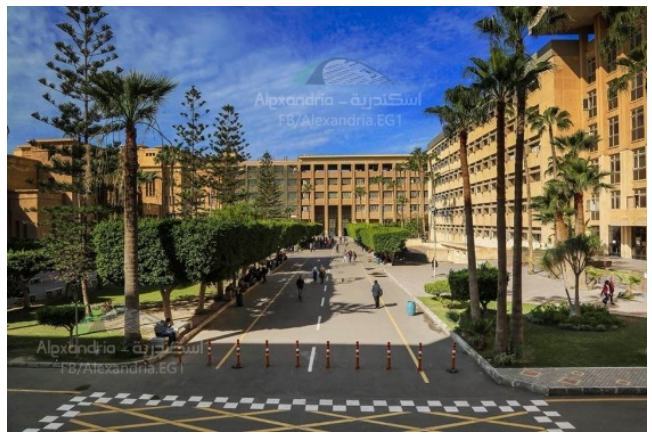

(c)

Figure 4: Landscape scenes from Faculty of Engineering, Alexandria University (EAU).

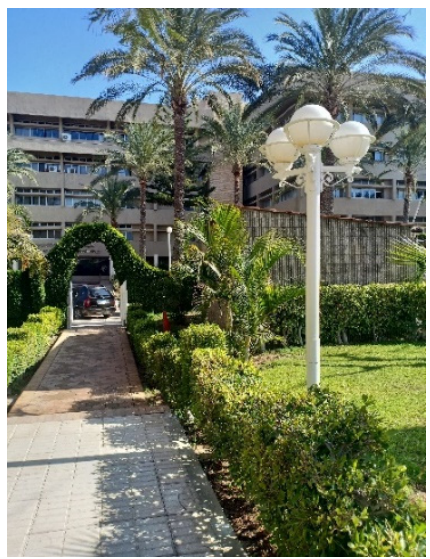

(a)

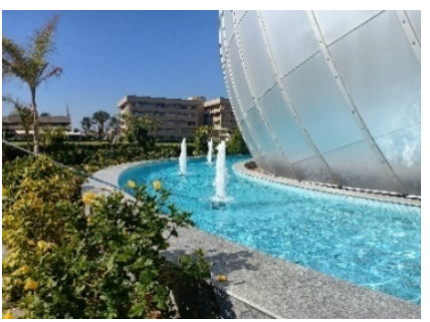

(b)

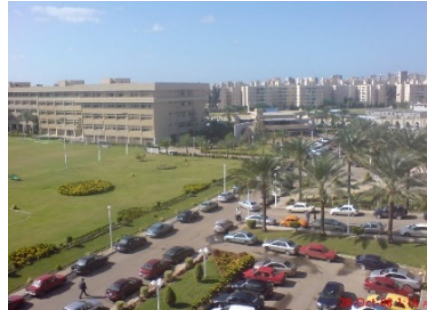

(c)

Figure 5: Landscape scenes from Arab Academy for Science and Technology (AAST). 


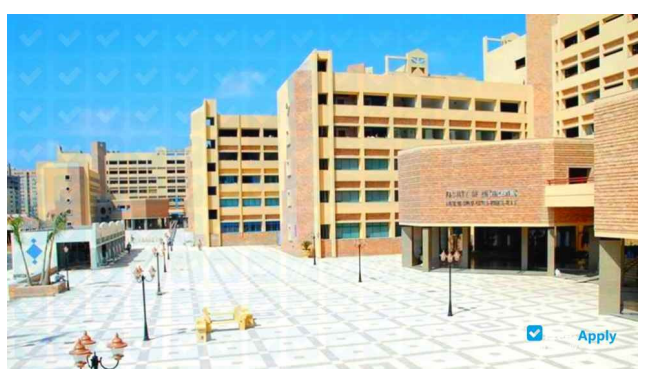

(a)

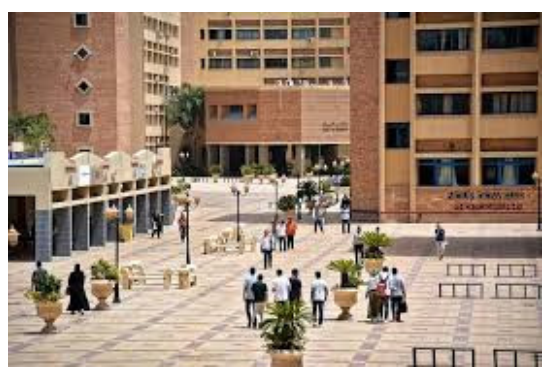

(b)

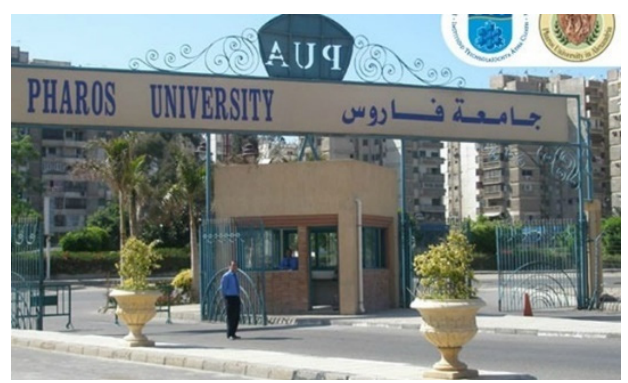

(c)

Figure 6: Landscape scenes from Pharos University in Alexandria (PUA).

Table 1: Comparing the landscape scenes from the three universities, according to the landscape preferences for preferable environments by Kaplan.

\begin{tabular}{|l|ccc|ccc|ccc|}
\hline LEEP & \multicolumn{3}{|c|}{ EAU } & \multicolumn{3}{c|}{ AAST } & \multicolumn{3}{c|}{ PUA } \\
\hline \multirow{2}{*}{ Complexity } & $4(\mathrm{a})$ & $4(\mathrm{~b})$ & $4(\mathrm{c})$ & $5(\mathrm{a})$ & $5(\mathrm{~b})$ & $5(\mathrm{c})$ & $6(\mathrm{a})$ & $6(\mathrm{~b})$ & $6(\mathrm{c})$ \\
& $\checkmark$ & $\boldsymbol{X}$ & $\checkmark$ & $\checkmark$ & $\checkmark$ & $\checkmark$ & $\boldsymbol{X}$ & $\boldsymbol{X}$ & $\boldsymbol{X}$ \\
\hline \multirow{2}{*}{ Coherence } & $4(\mathrm{a})$ & $4(\mathrm{~b})$ & $4(\mathrm{c})$ & $5(\mathrm{a})$ & $5(\mathrm{~b})$ & $5(\mathrm{c})$ & $6(\mathrm{a})$ & $6(\mathrm{~b})$ & $6(\mathrm{c})$ \\
& $\checkmark$ & $\checkmark$ & $\checkmark$ & $\checkmark$ & $\checkmark$ & $\boldsymbol{X}$ & $\boldsymbol{X}$ & $\checkmark$ & $\checkmark$ \\
\hline \multirow{2}{*}{ Legibility } & $4(\mathrm{a})$ & $4(\mathrm{~b})$ & $4(\mathrm{c})$ & $5(\mathrm{a})$ & $5(\mathrm{~b})$ & $5(\mathrm{c})$ & $6(\mathrm{a})$ & $6(\mathrm{~b})$ & $6(\mathrm{c})$ \\
& $\checkmark$ & $\boldsymbol{X}$ & $\checkmark$ & $\checkmark$ & $\checkmark$ & $\boldsymbol{X}$ & $\boldsymbol{X}$ & $\checkmark$ & $\checkmark$ \\
\hline \multirow{2}{*}{ Mystery } & $4(\mathrm{a})$ & $4(\mathrm{~b})$ & $4(\mathrm{c})$ & $5(\mathrm{a})$ & $5(\mathrm{~b})$ & $5(\mathrm{c})$ & $6(\mathrm{a})$ & $6(\mathrm{~b})$ & $6(\mathrm{c})$ \\
& $\checkmark$ & $\boldsymbol{X}$ & $\boldsymbol{X}$ & $\boldsymbol{X}$ & $\checkmark$ & $\checkmark$ & $\checkmark$ & $\checkmark$ & $\boldsymbol{X}$ \\
\hline
\end{tabular}

According to the previous comparison in Table 1, the landscape scene with the most landscape preferences achieved in each campus was decided to be the scene sent for the students with the questionnaire.

From the Table 1, we can deduce that in the Faculty of Engineering, Alexandria University, the scene with the most implemented preferences is 4(a), where the four landscape preferences by Kaplan are implemented, while scene 5(b) is the one with the four preferences implemented in AAST, and scene 6(b) in PUA where three of the four preferences were implemented. 


\subsubsection{Data collection and questionnaires}

Based on the literature review, campus landscape elements were listed and the different emotions students can feel during their campus landscape experience were discussed, accordingly, a questionnaire was conducted, where 65 students were asked to answer the 45 questions while viewing the scene from their campus that was chosen from the comparison in phase one. The questionnaires were sent online and filled by more than 65 students from the three chosen universities. The ages of the students who filled the questionnaire ranged from 21 to 25 years old, $70 \%$ of the students were females while the rest were males.

Students' engagement in decision making and their opinions are from the most important factors in the success of any institution. Every student was required to view the scene from his campus that was chosen in phase one according to Kaplan's landscape preferences, and then answer the questionnaire based on the scene he viewed. The questionnaire was divided into three sections; the first section was for gathering general information about the students, where the ages of students, genders, and which university campuses did they attend were questioned. The second section was the main part relating landscape elements to students' emotions, in this part students were asked about each landscape element, whether is it available in their campus or not, how they use it, the way it was designed, and its suitability for being usable, and lastly, at the end of each landscape element questions, a question about the emotion/s the students feel towards using or viewing this landscape element. The third section, and the last one, was about the students' opinions on the effect of their emotional states on their academic performance and achievements.

The results of the questionnaire were then represented into a two-dimensional matrix correlating students' emotions on using the different landscape elements on campus.

\section{RESULTS}

\subsection{Students' questionnaires}

The results of the students' questionnaire are represented in the Landscape and Emotions matrix, as the questionnaire results approve the validity of the results of the literature review studies of the emotions experienced on student-landscape interaction.

\subsection{Analysis of questionnaire results}

This matrix was based on the studies from the literature review section and the analysis of landscape elements and their benefits and uses on campus, and therefore their impact on students' emotions, and the validity of this matrix was checked by the results of students' questionnaires on their emotions during their campus landscape experience. The matrix shown in Table 2 was represented by symbols, where the $\checkmark$ symbol illustrates that from 40 to $100 \%$ of the participated students experienced the emotion while using the corresponding landscape element, the $\checkmark$ symbol represents the emotions of $10-40 \%$ of the participated students, while the empty cells represent $0-10 \%$ of the participated students experiencing the same emotion while using the corresponding landscape element.

\section{DISCUSSION}

The results of the questionnaire show that all the three components of emotions can be affected by landscape experience, although the subjective experience is the most affected component, as the personal factors interfere in human's reaction to viewing landscape 


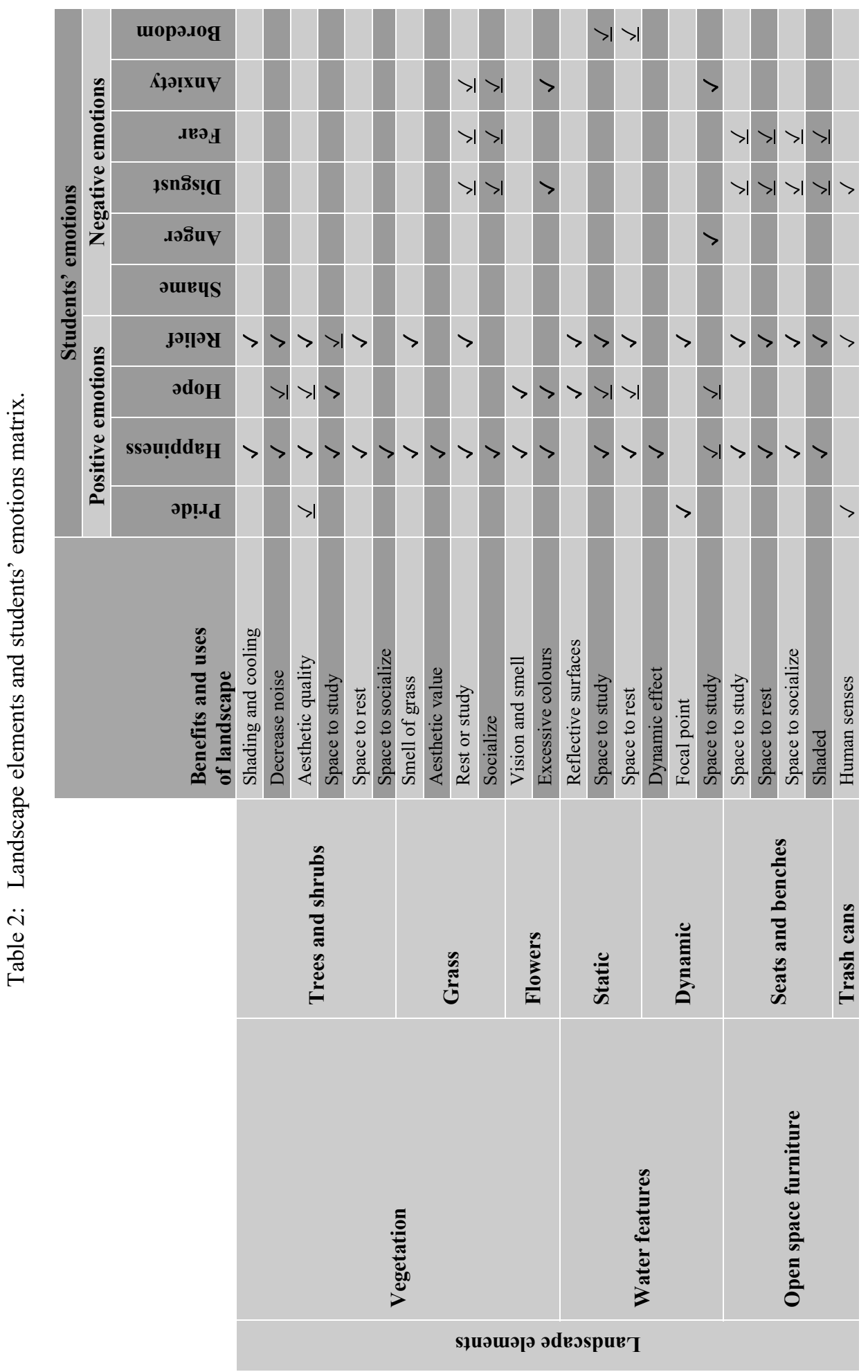




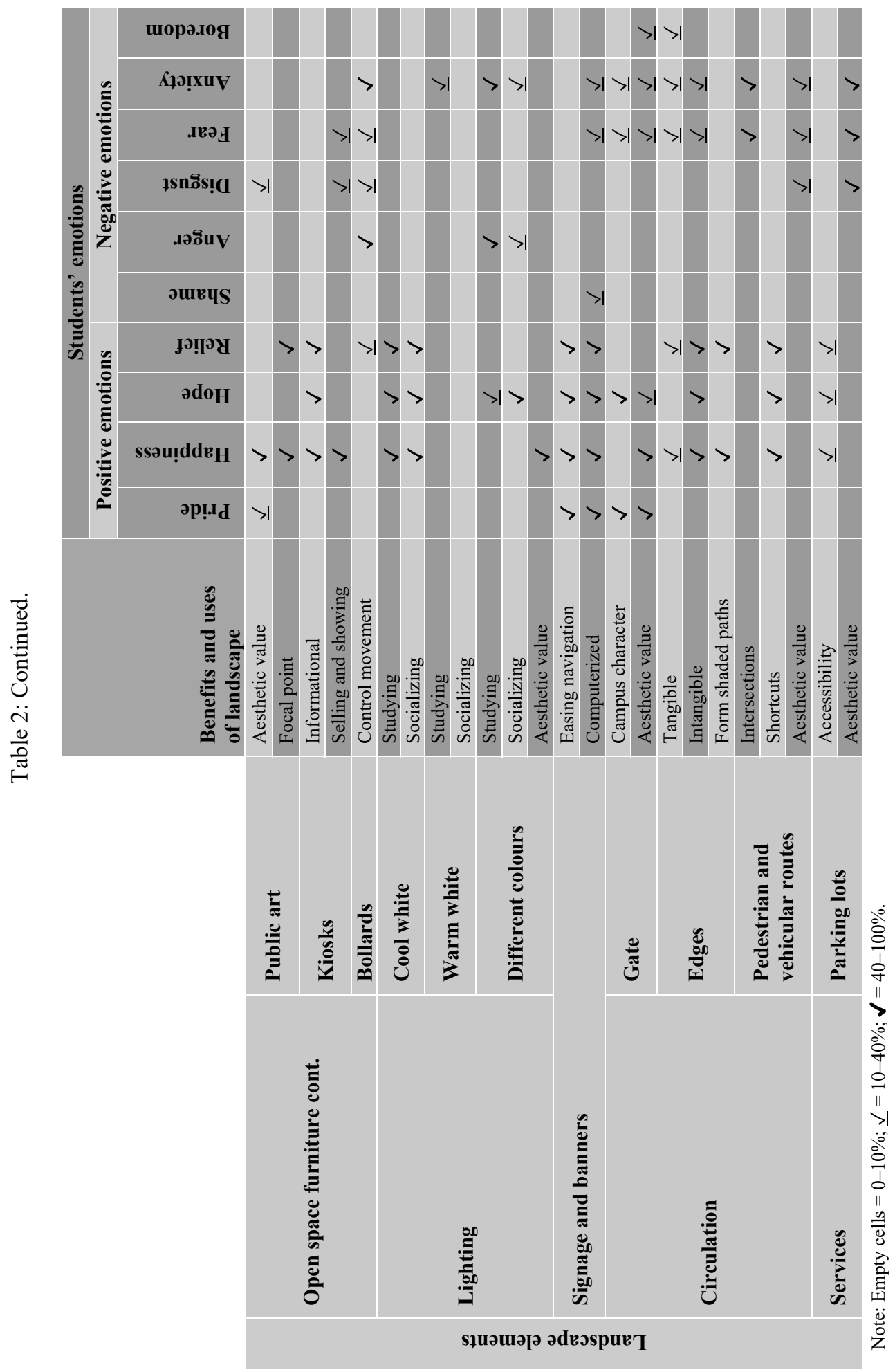


elements, as appeared in the questionnaire results, some students preferred different colors in trees or flowers, and others recommended using the shortcuts rather than walking in the passenger's walkways for easily reaching their destinations, but according to the majority of the students' answers, the psychological and the behavioral responses are also strongly affected due to the usage of landscape elements, as observed, when showed the landscape scenes in each campus, the landscape experience was often a positive emotions experience as long as the landscape elements are in the suitable locations and with the appropriate design standards and sufficiency. According to students' answers, landscape elements might also lead to negative emotions, this is mostly caused by the subjective experience of emotions where personal reasons take place, such as people who get scared of grass and they do not prefer sitting or walking on it, people who dislike shared seats and prefer sitting alone not in large groups, or people who hate specific colors in flowers. The psychological and behavioral responses also affect the negativity of experienced emotions during the landscape experience, as some of the landscape elements might cause anxiety or confusion such as dynamic water features near the studying area, other elements might cause the feeling of straining or suffocation such as solid edges surrounding the campus and the bollards that prevent from moving freely, lighting also might be a source of negative emotions when space is softly lit, whether, by natural or artificial light, it might give the feeling of relaxation which is not preferred for students on campus, it also might lead to boredom due to the excessed relaxing feeling.

\section{CONCLUSION}

In the educational sector, students' academic achievement was proven by research to be strongly affected by their emotions, which are influenced by several physical and mental factors. There is a strong relationship between emotion and environment, people might behave differently according to how space impacts their emotional response. While this area is being neglected in most of the previous research, the purpose of this study was to investigate the neglected human-landscape interaction from the psychological view. This study uses a qualitative analysis using a methodological and applicable framework of the emotional factor as a variable that is affected by the presence of landscape elements on campus to positively affect students' academic performance and enhance their academic achievements. Many variables could be considered when studying landscape effects on human emotions and psychological states, such as age and social, educational, and cultural backgrounds, however, this research focused on university campus students' emotions, whose ages and cultural backgrounds are mostly similar.

\section{ACKNOWLEDGMENTS}

Gratitude must be shown to God for helping in such a research, while facing so many obstacles and limitations, families for supporting and encouraging the hard work and for everyone who helped in easing the information gathering processes.

\section{REFERENCES}

[1] Anggiani, M. \& Heryanto, B., A study of informal space on campus by looking at student preferences. IOP Conference Series: Materials Science and Engineering, 453, 2018. https://doi.org/10.1088/1757-899X/453/1/012029.

[2] Mitchell, G., May, A. \& McDonald, A., PICABUE: A methodological framework for the development of indicators of sustainable development. Int. J. Sustain. Dev. World Ecol., 2, pp. 104-123, 1995. https://doi.org/10.1080/13504509509469893. 
[3] Meyer, D.K. \& Turner, J., Discovering emotion in classroom motivation research. Educ. Psychol., 37, pp. 95-105, 2002. https://doi.org/10.1207/S15326985EP3702.

[4] Magid, A. \& Mohammed, M.I., The tree of emotions: Exploring the relationships of basic human emotions. Int. J. Indian Psychol., 5, 2017.

https://doi.org/10.25215/0501.123.

[5] Dober, R.P., Campus Landscape: Functions, Forms, Features, Wiley, 2013.

[6] Hockenbury, D.H. \& Hockenbury, S.E., Discovering Psychology, 2010.

[7] Giacomoni, P., Descartes' emotions: From the body to the body. Rivista Internazionale di Filosofia e Psicologia, 8, pp. 14-29, 2017. https://doi.org/10.4453/rifp.2017.0002.

[8] Wrobel, M., Encyclopedia of Personality and Individual Differences, Springer: Cham, 2017. https://doi.org/10.1007/978-3-319-28099-8.

[9] Ekman, P., Basic emotions. Encycl. Personal. Individ. Differ., 1-6, 1999. https://doi.org/10.1007/978-3-319-28099-8_495-1.

[10] Song, H.Y., Siu, K.W.M. \& Liu, S., Cross-cultural values in street furniture emotion design. Proc. from 6th Conf. Des. Emot., pp. 1-28, 2008.

[11] Chafale, D. \& Pimpalkar, A., Sentiment analysis on product reviews using Plutchik's wheel of emotions with fuzzy logic. Int. J. Eng. Technol., 1, pp. 1-8, 2014.

[12] Pekrun, R., Goetz, T., Titz, W. \& Perry, R.P., Academic emotions in students' selfregulated learning and achievement: A program of qualitative and quantitative research. Educ. Psychol., 37(2), pp. 91-105, 2010. https://doi.org/10.1207/S15326985EP3702_4.

[13] Wilson, R., Managing emotions, 2019. https://camhs.huhs.harvard.edu/managingemotions. Accessed on: 30 Jun. 2020.

[14] Kalantari, F., Proposal of an operational model to measure feelings and emotions in urban space. Journal of Landscape Ecology, 12(3), pp. 34-52, 2019. https://doi.org/10.2478/jlecol-2019-0014.

[15] Ashihara, Y., Exterior Design in Architecture, Van Nostrand Reinhold, 1970.

[16] Rached, I. \& Elsharkawy, H., The role of open spaces in the university campus in the Egyptian context. Designing Place - International Urban Design Conference, Nottingham, UK, 2-3 Apr., pp. 1-15, 2012.

[17] Kaplan, S. \& Wendt, J.S., Preference and the visual environment: Complexity and some alternatives. Department of Psychology, University of Michigan, pp. 1-5, 1970.

[18] Menatti, L. \& Da Rocha, A.C., Landscape and health: Connecting psychology, aesthetics, and philosophy through the concept of affordance. Front. Psychol., 7, pp. 1-17, 2016. https://doi.org/10.3389/fpsyg.2016.00571.

[19] Law Olmsted, F., Forty Years of Landscape Architecture, 1985.

[20] Ayodele Emmanuel, I., Impact of quality and usage of outdoor spaces on sustainable campus environment in Akure, Nigeria. Am. J. Environ. Prot., 6, p. 105, 2017. https://doi.org/10.11648/j.ajep.20170605.11.

[21] Marvell, A. \& Simm, D., The emotional geographies of place: Developing effective learning and teaching strategies for fieldwork. Royal Geographical Society with IBG International Annual Conference, London, 2017.

[22] Matloob, F.A., Sulaiman, A.B., Ali, T.H., Shamsuddin, S. \& Mardyya, W.N., Sustaining campuses through physical character: The role of landscape. Procedia: Soc. Behav. Sci., 140, pp. 282-290, 2014. https://doi.org/10.1016/j.sbspro.2014.04.421. 